\begin{tabular}{|c|c|c|c|}
\hline \multirow{3}{*}{$\begin{array}{r}\text { Case Reports in } \\
\text { Gastroenterology }\end{array}$} & \multirow{2}{*}{\multicolumn{2}{|c|}{ Case Rep Gastroenterol 2019;13:134-139 }} & \multirow[b]{3}{*}{$\begin{array}{l}\text { Karger } \\
\text { Open'access }\end{array}$} \\
\hline & & & \\
\hline & $\begin{array}{l}\text { DOI: 10.1159/000498907 } \\
\text { Published online: March 7, } 2019\end{array}$ & $\begin{array}{l}\text { (c) } 2019 \text { The Author(s) } \\
\text { Published by S. Karger AG, Basel } \\
\text { www.karger.com/crg }\end{array}$ & \\
\hline & $\begin{array}{l}\text { This article is licensed under } t \\
\text { International License (CC BY-NC } \\
\text { Usage and distribution for comm }\end{array}$ & $\begin{array}{l}\text { mons Attribution-NonCommercial } 4.0 \\
\text { rger.com/Services/OpenAccessLicense). } \\
\text { quires written permission. }\end{array}$ & \\
\hline
\end{tabular}

\title{
Esophageal Stenosis in a Patient with Lichen Planus
}

\author{
Bruna Rosic Despalatovic ${ }^{a} \quad$ Andre Bratanic $^{b} \quad$ Zeljko Puljiz $^{b}$ \\ Jasminka Bozikovic ${ }^{a}$ \\ a \& $\mathrm{J}$ MEDICI" Polyclinic for Internal Medicine, Split, Croatia; bepartment of \\ Gastroenterology and Hepatology, Split, Croatia
}

\section{Keywords}

Lichen planus · Esophagus · Stenosis

\begin{abstract}
Lichen planus is a chronic, idiopathic disorder which usually affects skin and mucosal surfaces. While oral mucosa is frequently involved, esophageal localization is uncommon, and it usually manifests with dysphagia. It has also been associated with squamous cell carcinoma. Underdiagnosing of esophageal lichen planus often leads to a delay in treatment. There are also no clear recommendations for treatment of this disorder. Systemic corticosteroids are usually the first-line therapy, but different other therapeutic approaches are also used, with a various rate of response. We present the case of a patient with esophageal lichen planus complicated with esophageal stenosis, who was rather resistant to treatment.

(C) 2019 The Author(s) Published by S. Karger AG, Basel
\end{abstract}

\section{Introduction}

Lichen planus (LP) is a chronic, idiopathic inflammatory disease which mostly affects the skin, mucous membranes, and nails [1,2]. According to different estimations, this disorder appears in $0.5-2 \%$ of the population, with a predilection for females in their forties and fifties $[1,3]$. The cutaneous forms of the disease affect the skin, scalp, and nails, while mucosal forms usually affect the mouth, pharynx, and perineum. Mucosal forms are found in 30-70\% of the patients. Esophageal involvement in LP is rarely found, the true prevalence being difficult to 
estimate due to subtle clinical changes and lack of characteristic histologic features [4]. Esophageal localization of the disease usually manifests with dysphagia due to upper esophageal lesions and stenoses. In these patients, previous oral lesion is often observed for a prolonged period of time [5-7]. Risk of development of squamous cell carcinoma is unknown for esophageal lichen planus (ELP), but it is strongly suspected that it is increased $[1,8]$. There are only few case reports of ELP in the medical literature up to date, and these patients represent considerable diagnostic and therapeutic challenge for clinicians [4]. In our case, we present a 71year-old patient with ELP, complicated with stenosis, who proved to be rather resistant to a treatment.

\section{Case Report}

Three years ago, a 71-year-old female patient, with a history of arterial hypertension and hyperlipidemia, was referred to an oral pathologist, after hyperkeratotic areas and aphthous lesion of buccal mucosa had been observed by her dentist. Buccal changes were accompanied by dryness and pain in the oral cavity (Fig. 1). Biopsy was performed, and pathohistological analysis found a hyperkeratotic epithelium with elongated epidermal extensions and apoptotic keratinocytes, a finding which was consistent with LP (Fig. 1). After that, the patient was treated with local solutions, including dexamethasone and hexetidine, by an oral pathologist.

After a year, in spite of treatment, dysphagia developed due to solid food first and later even due to liquids. Oral cavity lesions were still present. At this point, the patient was referred to a gastroenterologist. On esophagogastroscopy, circular stenosis in the upper third of the esophagus was found, esophageal lumen being reduced to $1 \mathrm{~cm}$, and its surface covered with pseudomembranaceous layers (Fig. 2). Samples were taken during the endoscopy, and pathohistological analysis showed stromal infiltration with granulocytes and the presence of foreign-body gigantic cells. Radiologic studies were also performed, and they showed 9-cm-long esophageal stenosis with a lumen reduction to $5 \mathrm{~mm}$, while CT revealed thickening of the esophageal wall (Fig. 3).

Considering the results of a diagnostic workup, and after excluding malignant stenosis, systemic corticosteroid therapy was initiated (64 mg methylprednisolone with subsequent dose tapering). After a month of treatment, there was a complete resolution of buccal changes, but dysphagia persisted along with endoscopically confirmed stenosis. At this point, endoscopic dilation of stenosis was performed with satisfactory results. Corticosteroid therapy had been tapered down and terminated, and the patients was symptomless.

Six months after stopping therapy, the patient presented with mild dysphagia and with radiologically confirmed 6 -cm-long esophageal stenosis (luminal diameter of $8 \mathrm{~mm}$ ). Buccal efflorescences were also present again.

Systemic corticosteroid therapy was reintroduced (32 mg methylprednisolone with subsequent dose tapering to $12 \mathrm{mg}$ ), along with topical tacrolimus therapy for oral cavity lesions. This therapy was continued for the next 8 months and is still under way. At present, there is no dysphagia nor buccal changes in the patient. Control endoscopic examination revealed an improvement of mucosal changes, but stenosis is still not passable for endoscope (Fig. 2). 


\section{Discussion}

LP is an idiopathic disorder of the squamous epithelium. Prevalence rates differ among studies [3, 6]. There is a predilection for the disease in middle-aged female patients [9]. Esophageal localization of LP is an extremely rare disease with only about 50 cases reported up to date, clinically presenting itself most frequently as dysphagia ( $81 \%$ of patients), followed by odynophagia (24\%), and weight loss (14\%) [1,9]. This disorder often also goes undetected, being misdiagnosed as esophageal reflux disease. Endoscopic examination is, therefore, crucial for establishing diagnosis [1]: firstly, because ELP typically affects the proximal esophagus, as in our case, leaving the gastroesophageal junction intact, thus differing from esophageal reflux disease; secondly, by endoscopy we can observe changes such as pseudomembranes, friable mucosa, papules, ulcerations or stenoses. According to some recent studies, esophageal involvement is much more frequent in LP, given that clinical and pathologic findings are assessed carefully [10]. All aforementioned epidemiological and clinical characteristics were present in our patient. In addition, there were pseudomembranes and stenosis present at initial endoscopic evaluation $[4,11]$.

Data on histopathology of ELP is scarce [12]. Although there are characteristic histologic findings in ELP, such as basal keratinocyte degeneration or bandlike (lichenoid) lymphocytic infiltrate involving the superficial lamina propria and basal epithelium, it is generally known that, for difference from cutaneous LP, histopathological results in ELP are often variable and inconclusive [1, 4]. In our case, the histopathological analysis of the buccal mucosa sample showed a hyperkeratotic epithelium with elongated epidermal extensions and apoptotic keratinocytes, a finding consistent with LP, but later histopathological analysis of samples taken from the esophagus showed only a stromal infiltration with granulocytes and the presence of foreign-body gigantic cells, which are rather nonspecific. Therefore, it is necessary for clinicians to establish a diagnosis relying on an appropriate clinical and endoscopic approach, often without or with only suggestive histopathological findings.

Considering a therapeutic approach in this disease, we can see that there are no well-established guidelines to treat ELP [13]. For advanced and symptomatic cases, systemic corticosteroids are usually given, with a response rate of up to $74 \%$, but also with a high relapse rate (up to 85\%) after therapy discontinuation $[9,12]$. According to different studies, local (intralesional) corticosteroids and cyclosporine, topical tacrolimus, and adrenocorticotropic hormone also achieved a certain treatment response $[5,10]$. There is a recent case series in which symptomatic and endoscopic improvement was reported after treatment with swallowed fluticasone propionate [8]. If there is stenosis, esophageal dilation is commonly used, and an additional intralesional corticosteroid injection can decrease the need for repeated dilation $[4,11]$. In our clinical case, we used systemic corticosteroid therapy along with esophageal dilation, but only with partial and transient response. After clinical and endoscopic relapse, we reintroduced systemic corticosteroid therapy along with topical tacrolimus for a prolonged period of time, with only suboptimal results.

In conclusion, although ELP is a rare disorder, it should be suspected in patients with dysphagia and mucosal abnormalities of the upper third of the esophagus, especially in female patients in their forties. After diagnosing, therapeutic options should be considered: primarily systemic corticosteroids or swallowed fluticasone, but also an esophageal dilation in case of stenosis. These patients should also be closely followed up because of the risk of malignant transformation (squamous carcinoma). 
Rosic Despalatovic et al.: Esophageal Lichen Planus

\section{Statement of Ethics}

All procedures were performed in accordance with ethical standards required by the Declaration of Helsinki. Informed consent was obtained from the patient.

\section{Disclosure Statement}

Authors declare that they have no conflict of interest.

\section{Author Contributions}

All authors took part in data collection, data analysis, and manuscript preparation.

\section{References}

1 Oliveira JP, Uribe NC, Abulafia LA, Quintella LP. Esophageal lichen planus. An Bras Dermatol. 2015 MayJun;90(3):394-6.

2 Berger TG. Lichen planus. JAMA Dermatol. 2015 Mar;151(3):356.

3 Katzka DA, Smyrk TC, Bruce AJ, Romero Y, Alexander JA, Murray JA. Variations in presentations of esophageal involvement in lichen planus. Clin Gastroenterol Hepatol. 2010 Sep;8(9):777-82.

4 Chandan VS, Murray JA, Abraham SC. Esophageal lichen planus. Arch Pathol Lab Med. 2008 Jun;132(6):1026-9.

5 Westbrook R, Riley S. Esophageal lichen planus: case report and literature review. Dysphagia. 2008 Sep;23(3):331-4.

6 Nielsen JA, Law RM, Fiman KH, Roberts CA. Esophageal lichen planus: a case report and review of the literature. World J Gastroenterol. 2013;19(14):2278-81.

7 Harewood GC, Murray JA, Cameron AJ. Esophageal lichen planus: the Mayo Clinic experience. Dis Esophagus. 1999;12(4):309-11.

8 Ynson ML, Forouhar F, Vaziri H. Case report and review of esophageal lichen planus treated with fluticasone. World J Gastroenterol. 2013 Mar;19(10):1652-6.

9 Franco DL, Islam SR, Lam-Himlin DM, Fleischer DE, Pasha SF. Presentation, diagnosis and managment of esophageal lichen planus: a series of six cases. Case Rep Gastroenterol. 2015 Jul;9(2):253-60.

10 Kern JS, Technau-Hafsi K, Schwacha H, Kuhlmann J, Hirsch G, Brass V, et al. Esophageal involvement is frequent in lichen planus: study in 32 patients with suggestion of clinicopathologic diagnostic criteria and therapeutic implications. Eur J Gastroenterol Hepatol. 2016 Dec;28(12):1374-82.

11 Chryssostalis A, Gaudric M, Terris B, Coriat R, Prat F, Chaussade S. Esophageal lichen planus: a series of eight cases including a patient with esophageal verrucous carcinoma. A case series. Endoscopy. 2008 Sep;40(9):764-8.

12 Parvez M, Rai V, Khan EM, Goenka MK. Esophageal lichen planus: A rare and under-recognized disorder. J Dig Endosc. 2016;7(1):33-5.

13 Eustace K, Clowry J, Kiely C, Murphy GM, Harewood G. The challenges of managing refractory oesphageal lichen planus. Ir J Med Sci. 2015 Mar;184(1):75-6. 


\section{Case Reports in Gastroenterology}

\begin{tabular}{l|l}
\hline Case Rep Gastroenterol 2019;13:134-139 \\
\hline DOI: 10.1159/000498907 & $\begin{array}{l}\text { @ 2019 The Author(s). Published by S. Karger AG, Basel } \\
\text { www.karger.com/crg }\end{array}$ \\
\hline
\end{tabular}

Rosic Despalatovic et al.: Esophageal Lichen Planus
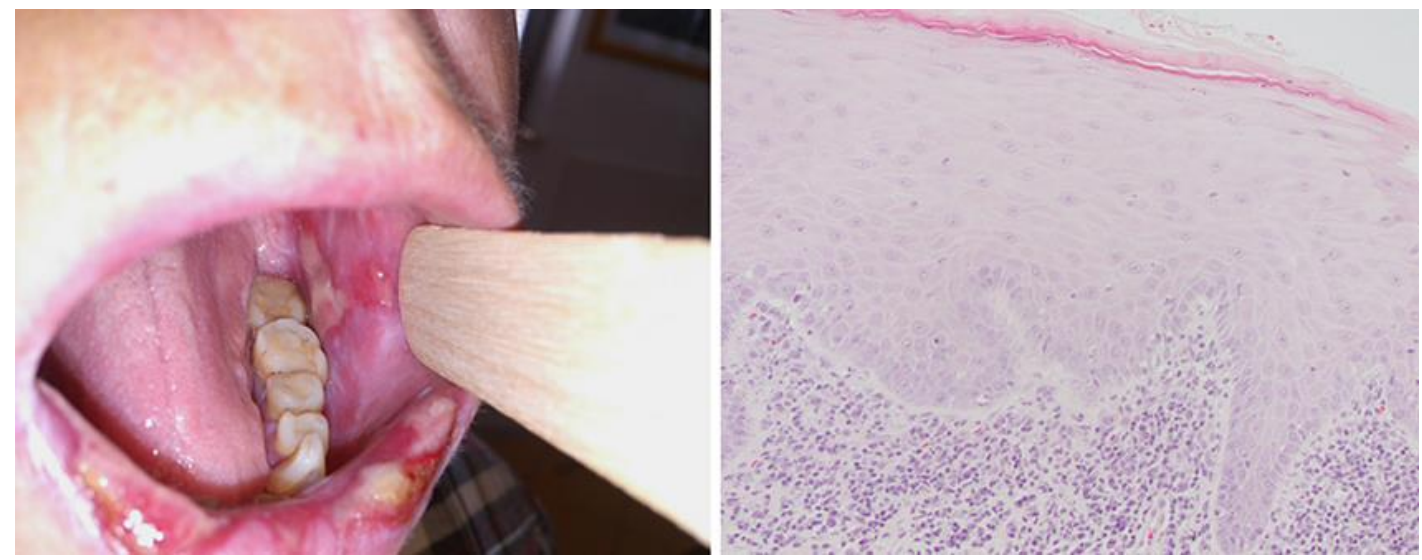

Fig. 1. Clinical and histopathological (magnification $\times 200$, hematoxylin and eosin stain) appearance of buccal mucosa changes.

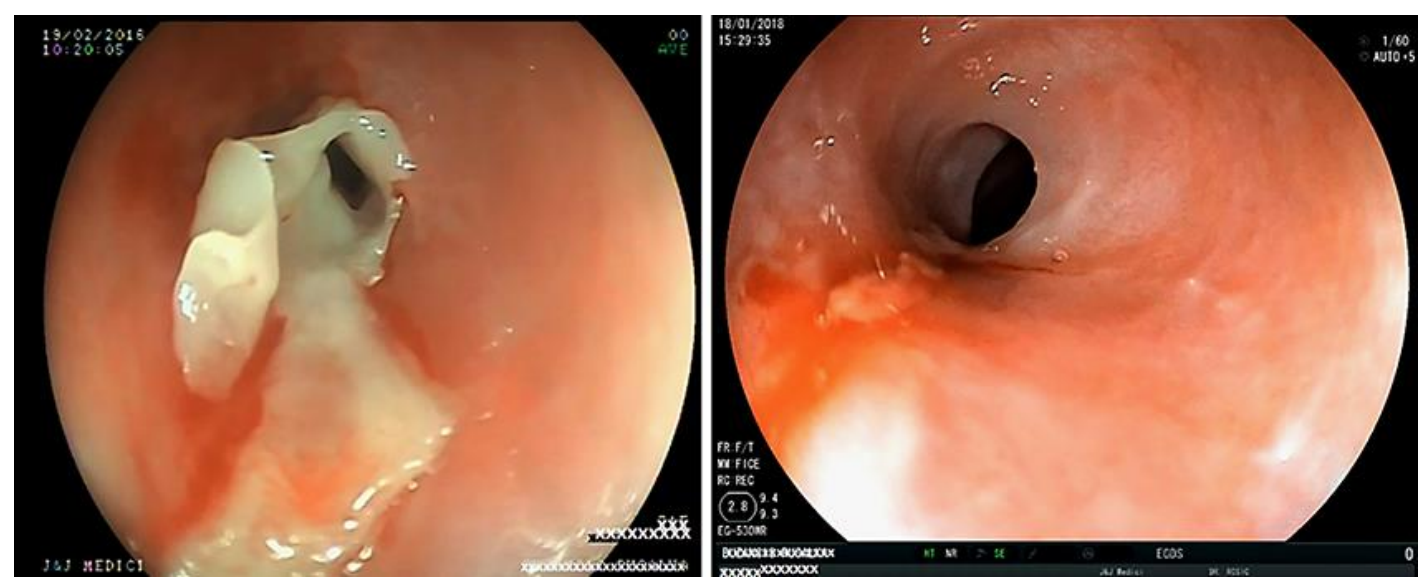

Fig. 2. Endoscopic view of the esophagus before and after dilation and systemic corticosteroid treatment. 


\begin{tabular}{|c|c|c|}
\hline \multirow{2}{*}{$\begin{array}{l}\text { Case Reports in } \\
\text { Gastroenterology }\end{array}$} & \multicolumn{2}{|c|}{ Case Rep Gastroenterol 2019;13:134-139 } \\
\hline & DOI: 10.1159/000498907 & $\begin{array}{l}\text { O } 2019 \text { The Author(s). Published by S. Karger AG, Basel } \\
\text { www.karger.com/crg }\end{array}$ \\
\hline
\end{tabular}

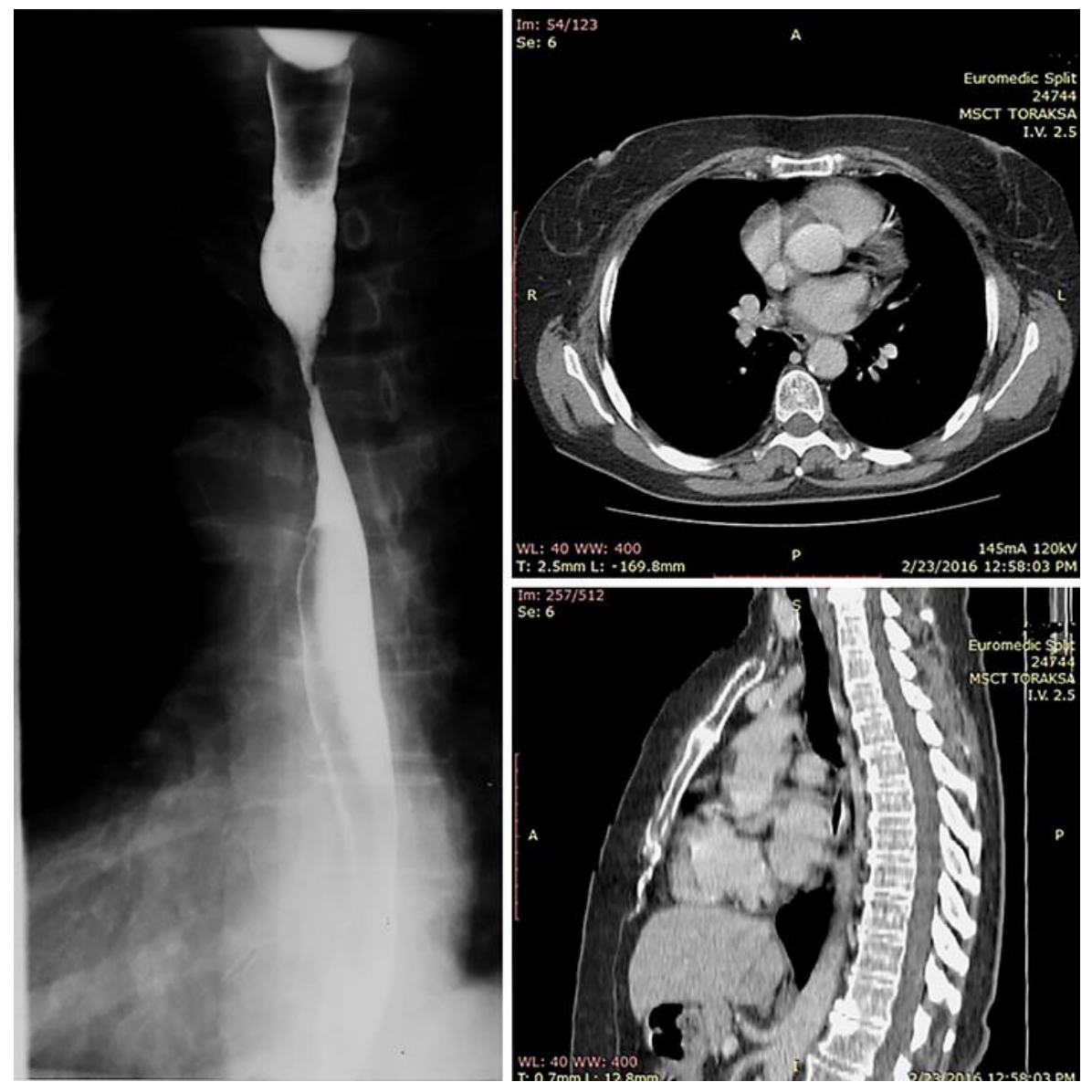

Fig. 3. Contrast radiography and CT scan of esophageal stenosis. 